\title{
The association between character of portal blood flow and post-TIPS incidence of hepatic encephalopathy
}

\author{
Helmy El-Shazly ${ }^{1}$, Mohamed Abdel-Samiee ${ }^{1,3^{*}}$ (D, El-Sayed Tharwa ${ }^{1}$, Hassan Zaghla ${ }^{1}$, Shrief Abass ${ }^{1}$, \\ Mohamed El-Warraky ${ }^{2}$ and El-Sayed Ibrahim ${ }^{1}$
}

\begin{abstract}
Background: Hepatic encephalopathy (HE) is one of the serious complications observed post-TIPS operations in patients with different complications of portal hypertension such as refractory ascites, refractory hydrothorax, bleeding varices, and hepato-renal syndrome. Herein, we aimed to clarify predisposing factors for post-TIPS incidence of HE according to pre-TIPS hemodynamics.

Results: Fifty patients were enrolled in this study with different complications of portal hypertension; most of them have Child A and B scores. Patients were evaluated by ultrasound Doppler for the flow inside the portal vein and clinically recorded into two groups: group 1, 31 patients with hepatopetal flow; and group 2, 19 patients with hepatofugal flow. Then, TIPS was performed and patients were reassessed 1 month later to detect HE. Multiple variables such as age, gender, etiology of liver disease, and indication for TIPS had no significant differences. The incidence of HE post-TIPS was observed more at group 1 more than at group $2(P=0.02)$.

Conclusions: Post-TIPS incidence of HE was interestingly related to pre-TIPS flow in the portal vein (hepatopetal group more than hepatofugal group). Patients with hepatofugal flow in the portal vein are perfect candidate for TIPS than patients with hepatopetal flow in the portal vein. Patients with previous history of HE are contraindicated for TIPS except as a bridge for liver transplantation.
\end{abstract}

Keywords: Portal hypertension, Ultrasound Doppler, Flow inside the portal vein, TIPS, HE

\section{Background}

In 1980, the transjugular intrahepatic portosystemic shunt (TIPS) was developed to reduce complications of portal hypertension. Therefore, TIPS was rapidly applied to the treatment of many of the complications of portal hypertension when the shunt could be placed with relative ease. These complications include active bleeding of gastro-esophageal varices, control of refractory cirrhotic ascites and hepatic hydrothorax, and treatment of

\footnotetext{
* Correspondence: Drmohammed100@yahoo.com

${ }^{1}$ Hepatology and Gastroenterology Department, National Liver Institute,

Menoufia University, Yassin Abdel-Ghafar street, Shebeen El-Kom, Menoufia 32511, Egypt

${ }^{3}$ National Liver Institute, Menoufia University, Shebeen El-Kom, Egypt

Full list of author information is available at the end of the article
}

hepatorenal failure and hepato-pulmonary syndrome [1, 2]. Hepatic encephalopathy (HE) is a well-known complication of patients with liver cirrhosis after TIPS; its pathogenesis is not well understood [3, 4]. In the last decade, substantial progress has been made in the treatment of portal hypertension and its associated complications. TIPS has been considered as a minimally invasive therapy for portal hypertension complications [5-7]. From the clinical point of view, TIPS resembles a surgical side to side shunt leading to an increased rate of $\mathrm{HE}$ which can be seen after TIPS. The incidence of HE after TIPS varies from 18 to $45 \%$ [8-10].

This high rate attracts researchers in investigating the causative factors for $\mathrm{HE}$ besides predicting factors of $\mathrm{HE}$ after TIPS which had been much controversial. The 
study aimed to verify the relationship between pretransjagular intrahepatic portosystemic shunt intrahepatic hemodynamics and the incidence of post-transjagular intrahepatic portosystemic shunt hepatic enchephalopathy.

\section{Methods}

Fifty patients were included in this prospective singlecenter study with different causes of portal hypertension; patients underwent TIPS in the National Liver Institute, Menoufia University, from 2015 to 2017. Patients were divided into two groups according to the flow inside the portal vein by Doppler: group I-31 patients with hepatopetal flow (Toward the Liver), and group II-19 patients with hepato-fugal flow (away from the liver).

The day before the procedure, a basal evaluation of HE including examination and grading of the patients' mental state, asterixis, and psychometric performance (trail-making test-A, TMT-A), as well as their venous blood ammonia determination, were carried out. The evaluation of the degree of HE was based on the alteration of the patient's mental state using modifications of the West Haven criteria. The mental state was assessed in each patient by the same investigator using standardized tests and questions.

\section{TIPS}

A catheter was inserted via the jugular vein past the right atrium and into the hepatic veins. A needle was then inserted into the hepatic parenchyma, and contrast was injected as the needle was slowly withdrawn. When a branch of the portal vein was identified, a wire was inserted into the vein followed by a catheter. Pressures were obtained, and portography was performed. Before shunt placement, the pressure gradient is measured by calculating the difference in pressure between the wedged catheter and after placing the catheter freely in the hepatic vein. After shunt placement, the pressure gradient is measured by calculating the difference in pressure measured directly while the catheter is in the portal vein and after withdrawal of the catheter to the hepatic vein. A tract within the hepatic parenchyma was then created using a balloon and stent deployed. The used stents were self-expanding.

\section{Follow-up}

Patients were followed up at the hospital for 1 week then discharged and followed up for another 3 weeks for the incidence of HE. Hepatic encephalopathy was diagnosed and graded according to the "West Haven criteria" as moderate (grades I-II) and severe (grades III-IV). Episodic hepatic encephalopathy was defined as the sporadic occurrence of alteration in the neuropsychiatric function that develops over a short period of time.

\section{Statistical analysis}

The data collected were tabulated and analyzed by SPSS

(Statistical Package for Social Sciences) version 22.0 on

IBM compatible computer.

Two types of statistics were done:

Descriptive statistics:

- For example, percentage (\%), mean, and standard deviation (SD).

Analytic statistics:

- For example, chi-square test $\left(\chi^{2}\right)$ was used to study the association between two qualitative variables.

- Fischer exact test for $2 \times 2$ tables when expected cell count of more than $25 \%$ of cases was less than 5 and $p$ value $<0.05$ was considered significant.

- Student $t$ test is a test of significance used for comparison between two groups having quantitative variables.

- Mann-Whitney test (nonparametric test) is a test of significance used for comparison between two groups not normally distributed having quantitative variables.

- Paired $t$ test is a test of significance used for comparison between two related groups having quantitative variables.

\section{Results}

The etiology of portal hypertension was more in postHCV (70\%), HBV (4\%), HCV, and HBV (8\%), then Bilharizial periportal fibrosis $(18 \%)[11,12]$. There are 20 males and 30 females with no significant difference in the incidence of post-TIPS; there was no statistically significant difference as regards gender ( $p$ value 0.41 ) (Table 1). The liver function has no significant difference except in calculating the Child score. The kidney function is important; the more increase in creatinine level and HRS, the more the post-TIPS ( $p$ value 0.14 ; this indicates the more cirrhosis and portal hypertension and ascites in these patients only, with no clinical importance in post-TIPS HE).

The most common indication of TIPS is refractory ascites $(64 \%)$ then refractory, hydrothorax $(20 \%)$ then refractory, and bleeding varices (12\%) then HRS (4\%), respectively, as shown in (Table 2). Patients who underwent TIPS with previous history of HE had HE postTIPS (100\%), and this shows that pre-TIPS HE is a significant predictor for post-TIPS HE as in Table 3. Thus, TIPS seems useful for the management of severe PHTrelated complications.

The higher the Child score, the more the post-TIPS incidence of HE, none of Child A (0\%), 9 patient of Child B (20\%), and two patients of Child C (100\%); this 
Table 1 Clinical characteristics of the studied groups before TIPS

\begin{tabular}{|c|c|c|c|c|c|c|}
\hline & \multicolumn{2}{|c|}{ Hepatofugal group (no. = 19) } & \multicolumn{2}{|c|}{ Hepatopetal group (no. = 31) } & \multirow[t]{2}{*}{$x^{2}$ test } & \multirow[t]{2}{*}{$P$ value } \\
\hline & No. & $\%$ & No. & $\%$ & & \\
\hline \multicolumn{7}{|l|}{ Gender } \\
\hline Male & 9 & 47.4 & 11 & 35.5 & \multirow[t]{2}{*}{0.69} & \multirow[t]{2}{*}{$0.41(>0.05)$} \\
\hline Female & 10 & 52.6 & 20 & 64.5 & & \\
\hline \multicolumn{7}{|l|}{ Ascites } \\
\hline Negative & 1 & 5.3 & 1 & 3.2 & \multirow[t]{4}{*}{0.43} & \multirow[t]{4}{*}{$0.94(>0.05)$} \\
\hline Mild & 1 & 5.3 & 3 & 9.7 & & \\
\hline Moderate & 4 & 21.1 & 6 & 19.4 & & \\
\hline Severe & 13 & 68.4 & 21 & 67.7 & & \\
\hline \multicolumn{7}{|c|}{ History of paracentesis } \\
\hline Negative & 1 & 5.3 & 4 & 12.9 & \multirow[t]{2}{*}{0.83} & \multirow[t]{2}{*}{$0.64(>0.05)$} \\
\hline Positive & 18 & 94.7 & 27 & 87.1 & & \\
\hline \multicolumn{7}{|c|}{ HE before TIPS } \\
\hline Negative & 19 & 100 & 29 & 93.5 & \multirow[t]{2}{*}{1.96} & \multirow[t]{2}{*}{$0.52(>0.05)$} \\
\hline Positive & 0 & 0 & 2 & 6.5 & & \\
\hline \multicolumn{7}{|l|}{ Child score } \\
\hline A & 2 & 10.5 & 2 & 6.5 & \multirow[t]{3}{*}{1.48} & \multirow[t]{3}{*}{$0.48(>0.05)$} \\
\hline B & 17 & 89.5 & 27 & 87.1 & & \\
\hline$C$ & 0 & 0 & 2 & 6.5 & & \\
\hline
\end{tabular}

HE hepatic encephalopathy, TIPS transjagular intrahepatic portosystemic shunts, No. number

relationship can tell us that patients with Child score less than $\mathrm{C}$ are fit for TIPS with fewer predictors for post-TIPS HE.

All patients with hepatopetal flow or hepatofugal flow had their mean arterial blood pressure decreased postTIPS especially in hepatopetal flow, and this indicates the change in the heamodynamics post-TIPS as shown in Table 3. The hepatic artery RI was more in the hepatofugal group than the hepatopetal group before TIPS. The hepatic artery RI decreased significantly post-TIPS in the hepatofugal group.

The pressure inside the inferior vein cava increased significantly post-TIPS due to shunting of the blood to a new way through the shunt and IVC. The pressure inside the portal vein decreased significantly post-TIPS also due to shunting most of the blood that passes

Table 2 Comparison between studied groups regarding indication of TIPS

\begin{tabular}{|c|c|c|c|c|c|c|}
\hline \multirow[t]{2}{*}{ Indication } & \multicolumn{2}{|c|}{$\begin{array}{l}\text { Hepatofugal } \\
\text { group } \\
(n=19)\end{array}$} & \multicolumn{2}{|c|}{$\begin{array}{l}\text { Hepatopetal } \\
\text { group } \\
(n=31)\end{array}$} & \multirow[t]{2}{*}{$x^{2}$ test } & \multirow[t]{2}{*}{$P$ value } \\
\hline & No. & $\%$ & No. & $\%$ & & \\
\hline Refractory ascites & 14 & 73.7 & 18 & 58.1 & 2.002 & 0.57 \\
\hline Refractory pleural effusion & 3 & 15.8 & 7 & 22.6 & & \\
\hline Refractory bleeding varices & 2 & 10.5 & 4 & 12.9 & & \\
\hline Hepatorenal syndrome & 0 & 0.0 & 2 & 6.5 & & \\
\hline
\end{tabular}

TIPS transjagular intrahepatic portosystemic shunts through it to the IVC. The incidence of HE was less in the hepatofugal flow group $(10 \%)$ than the hepatopetal flow group (29\%) (Tables 4, 5, and 6).

\section{Discussion}

Transjugular intrahepatic portosystemic stent-shunts (TIPS) have been increasingly used for the treatment of the complications of portal hypertension. A metaanalysis of randomized controlled trials confirms the superiority of TIPS over the endoscopic treatments in the prevention of variceal rebleeding but without any improvement in mortality [13]. Additionally, TIPS is effective in the resolution of refractory ascites in some patients [13]. But it remains unclear as to whether there is any survival advantage [14]. Hepatic encephalopathy is thought to result from intestinally derived toxins that bypass the normal metabolic pathways of the liver, either because of shunting of portal vein blood flow away from

Table 3 Comparison between the studied groups regarding post-HE

\begin{tabular}{|c|c|c|c|c|c|c|c|}
\hline & & \multicolumn{2}{|c|}{$\begin{array}{l}\text { Hepatofugal } \\
\text { group } \\
\text { (no. = 19) }\end{array}$} & \multicolumn{2}{|c|}{$\begin{array}{l}\text { Hepatopetal } \\
\text { group } \\
\text { (no. = 30) }\end{array}$} & \multirow[t]{2}{*}{$\begin{array}{l}\text { Fisher exact } \\
\text { test }\end{array}$} & \multirow[t]{2}{*}{$P$ value } \\
\hline & & No. & $\%$ & No. & $\%$ & & \\
\hline \multirow[t]{2}{*}{ Post HE } & Negative & 17 & 89.5 & 22 & 71.0 & 2.55 & 0.02 \\
\hline & Positive & 2 & 10.5 & 9 & 29.0 & & \\
\hline
\end{tabular}

HE hepatic encephalopathy, No. number 
Table 4 Comparison between the studied groups regarding MAP before and after

\begin{tabular}{lllll}
\hline & $\begin{array}{l}\text { Hepatofugal group } \\
\text { (no. }=19) \\
\text { Mean } \pm \text { SD }\end{array}$ & $\begin{array}{l}\text { Hepatopetal group } \\
\text { (no. }=30)\end{array}$ & $t$ test & $P$ value \\
\hline MAP before & $76.8 \pm 7.1$ & $80.9 \pm 7.5$ & 1.91 & 0.06 \\
MAP after & $76.4 \pm 6.2$ & $79.7 \pm 6.1$ & 1.85 & 0.07 \\
MELD & $11.7 \pm 3.3$ & $12.8 \pm 4.8$ & 0.46 & 0.64 \\
\hline
\end{tabular}

MAP mean arterial blood pressure, No. number, MELD model of end-stage liver disease

the liver parenchyma as in TIPS patients or because of the inability of the liver to handle such substances because of chronic hepatocellular disease. Certainly, both of these factors may play a role in patients with cirrhosis, with either one being more important [15].

Many studies have focused on the relevant factors of HE, but the effects of pre-/post-TIPS factors were found to be contradictory. The factors include pre-TIPS, age, liver function, pre-TIPS HE, Child score, and the direction of flow in the portal vein. In this study, we found that the occurrence of post-TIPS HE was closely related to the pre-TIPS portal blood flow direction; the low incidence of post-TIPS HE was observed in patients with hepatofugal portal blood flow $(n=2) 10 \%$, but high incidence in those with prograde (hepatopetal) portal blood flow $(n=9) 29 \%$, indicating that the pre-TIPS pattern of blood flow may greatly affect the occurrence of post-TIPS HE [16].

In the study done by Zuckerman et al. [17], the occurrence of HE after TIPS was independent of central venous pressures; portosystemic gradients (before and after TIPS); the direction of blood flow (before and after TIPS) in the right, left, and main portal veins; and the presence of encephalopathy after TIPS, and this is contrary to our results [17].

In a similar study done by Deng et al., the incidence of post-TIPS HE in the hepatofugal group $16 \%$ was lower than that in hepatopetal group 37\%, which agrees with our study [18].

Many studies agree that age more than 60 years old increases the incidence of post-TIPS HE. Sanyal et al. [19] stated that increasing age was significantly associated with encephalopathy, which agrees with our study [20].

In this study, we found that Child score was very important in the post-TIPS incidence of HE, with the Child score increasing, the more the post-TIPS incidence of HE. In this study, 4 patients had Child score A, none of them had post-TIPS HE; 44 patients had Child score B, 9 had post-TIPS HE; and 2 patients had Child score C, two had post-TIPS HE.

In a similar study by Sanyal et al., increasing Child class is significantly associated with post-TIPS HE, which agrees with our study [19].

Careful selection of patients for elective TIPS insertion is crucial, as is the experience of the center performing this procedure. TIPS is not recommended in patients with serum bilirubin $>3 \mathrm{mg} / \mathrm{dl}$ and low platelet count, current hepatic encephalopathy or chronic hepatic encephalopathy, concomitant active infection, progressive renal failure, severe systolic or diastolic dysfunction, or pulmonary hypertension.

In another study by Somberg et al., post-TIPS HE is associated with multivariate like hypoalbuminemia (albumin is one of the main variables in assessing Child score) [21].

In this study, we found that pre-TIPS incidence of HE is associated with post-TIPS incidence of HE as two patients had pre-TIPS HE and the two patients had postTIPS HE. In another study, those patients who developed clinically evident HE were significantly more likely to have a past history of encephalopathy and tended to be male $[8,22]$.

Past history of encephalopathy along with increasing age has previously been identified as important variables

Table 5 Comparison between the studied groups regarding liver functions before TIPS

\begin{tabular}{lllll}
\hline & $\begin{array}{l}\text { Hepatofugal group (no. = 19) } \\
\text { Mean } \pm \text { SD }\end{array}$ & $\begin{array}{l}\text { Hepatopetal group (no. = 31) } \\
\text { Mean } \pm \text { SD }\end{array}$ & $\begin{array}{l}\text { Mann-Whitney } \\
\text { test }\end{array}$ & $\begin{array}{l}P \text { value } \\
\text { ALT }(I \mathrm{U} / \mathrm{L})\end{array}$ \\
AST $(\mathrm{IU} / \mathrm{L})$ & $57.2 \pm 51.7$ & $40.5 \pm 35.1$ & 1.22 & $0.22(>0.05)$ \\
ALP $(\mathrm{IU} / \mathrm{L})$ & $57.6 \pm 50.3$ & $52.5 \pm 37.3$ & 0.62 & $0.54(>0.05)$ \\
Albumin(g/dL) & $136 \pm 66.4$ & $129.7 \pm 40.9$ & 0.09 & $0.93(>0.05)$ \\
T. Bilirubin (mg/dL) & $2.5 \pm 0.56$ & $2.8 \pm 1.03$ & 1.33 & $0.18(>0.05)$ \\
D. Bilirubin (mg/dL) & $1.5 \pm 0.58$ & $1.6 \pm 0.53$ & 0.62 & $0.54(>0.05)$ \\
INR & $0.95 \pm 0.77$ & $0.98 \pm 1.03$ & 0.22 & $0.83(>0.05)$ \\
$\mathrm{Na}^{+}$ & $1.46 \pm 0.22$ & $1.45 \pm 0.23$ & $0.23 \#$ & $0.82(>0.05)$ \\
$\mathrm{K}^{+}$ & $132.1 \pm 3.1$ & $130.2 \pm 4.2$ & $1.79 \#$ & $0.08(>0.05)$ \\
\hline
\end{tabular}

TIPS transjagular intrahepatic portosystemic shunts, No. number, ALT alanine aminotransferase, AST aspartate aminotransferase, INR international normalized ratio, $A L P$ alkaline phosphatase, $\mathrm{Na}$ sodium, $K$ potassium 
Table 6 Comparison of the studied variables in relation to post-TIPS incidence of hepatic encephalopathy

\begin{tabular}{|c|c|c|c|}
\hline \multirow[t]{2}{*}{ Variables } & \multicolumn{2}{|c|}{ Post TIPS hepatic encephalopathy } & \multirow[t]{2}{*}{$P$-value } \\
\hline & Negative & Positive & \\
\hline Age in years (mean $\pm S D$ ) & $44.67 \pm 7.38$ & $47.36 \pm 6.36$ & $0.372(>0.05)$ \\
\hline MAP (mean $\pm \mathrm{SD})$ & $79.10 \pm 7.96$ & $80.18 \pm 5.96$ & $0.663(>0.05)$ \\
\hline MELD score & $11.72 \pm 2.98$ & $14.73 \pm 7.16$ & $0.304(>0.05)$ \\
\hline HARI (mean \pm SD) & $0.58 \pm 0.10$ & $0.61 \pm 0.05$ & $0.459(>0.05)$ \\
\hline IVC pressure $\mathrm{mmHg}($ mean $\pm \mathrm{SD})$ & $5.18 \pm 0.89$ & $5.37 \pm 0.84$ & $0.403(>0.05)$ \\
\hline PVP mmHg (mean \pm SD) & $33.90 \pm 11.10$ & $34.45 \pm 5.66$ & $0.934(>0.05)$ \\
\hline
\end{tabular}

MAP mean arterial blood pressure, IVC inferior vena cava, MELD model of end-stage liver disease, HARI hepatic artery resistive index, PVP portal vein pulsatility

increasing the risk of post-TIPS HE [19] that goes with our study.

In another study, the mean age difference between patients with TIPS-related encephalopathy and other patients was not statistically significant $(P=0.11(>0.05))$. The statistical power of this test was only 0.35 ; therefore, we cannot guarantee that TIPS-related encephalopathy is independent of age, and a large sample would be required [23].

In this study, we found that there was no any significant difference between causes of TIPS in patients with portal hypertension and post-TIPS incidence of HE, except in HRS cases; we had 2 cases, and the two cases developed post-TIPS HE.

In a similar study by Zuckerman et al., the cause of liver disease had no interrelationship with patients with TIPSrelated HE, which agrees with our study in general [17].

In another study by Oliviero et al., serum creatinine level was the only variable related to the development of refractory $\mathrm{HE}$ at the logistic multivariate analysis. That agrees also with our study in the HRS cases, but we think that this issue needs more studies with more cases for more accurate results [24].

According to the hepatic artery RI, normally, when portal perfusion decreases, hepatic arterial blood may increase to maintain the relative invariableness of liver blood supply. This mechanism is called hepatic arterial buffer response (HABR). In this study, we found that before TIPS, the hepatic artery RI of patients of hepatopetal flow $(0.61 \pm 0.11)$ was significantly lower than that of hepatofugal group $(0.75 \pm 0.79)$ ( $P$ value 0.005$)$.

In a similar study by Deng et al., the hepatic artery RI of the patients before TIPS was lower than that of the patients with prograde flow, indicating the difference of post-TIPS intrahepatic hemodynamics, and this agree with our study [18].

Also, we found in this study that the hepatic artery RI in the hepatopetal group decreases after TIPS $(0.6 \pm 0.11$ before to $0.59 \pm 0.07$ after) but less than that in the hepatofugal group $(0.75 \pm 0.79$ before to $0.57 \pm 0.07$ after $)(P=$ 002); this indicates that there is a great change in the hemodynamics in the patient of the hepatofugal group after TIPS.
In a similar study by Deng et al. [18], hepatic hemodynamics of patients with hepatofugal portal flow only changed a little after TIPS and was still dependent on the hepatic artery perfusion. Therefore, the RI of the hepatic artery was changed a little before and after TIPS, and this contrary to our study; although in patients with hepatofugal flow, large spontaneous portosystemic anastomosis could be found, and more importantly, the long-term existence of small to large pre-TIPS spontaneous portosystemic anastomoses might enable the cerebrum to adapt to some neurotoxic substances in the blood, which causes HE [18]. The lack of control subjects, however, does limit the ability to evaluate this approach.

According to post-TIPS hemodynamics and mean arterial blood pressure (MAP) before and after in this study, we found that MAP of patients with hepatofugal flow $(76.8 \pm 7.1)$ was less than those with hepatopetal flow $(80.9 \pm 7.5)$; also, we found that the MAP decreased after TIPS, and the decrease was more in patients with hepatopetal flow more than that of hepatofugal flow. All these results indicate that there is an alteration in the hemodynamic in patients post-TIPS more in patients with hepatopetal flow, and this may explain the high rate of post-TIPS HE.

Another study showed that the average MAP was (92 $\mathrm{mmHg}$ ) before TIPS; a tendency of MAP to increase after TIPS replacement was noted $(100 \mathrm{mmHg})$, but the difference was not significant. Two months later, it decreased to a value lower than the baseline $(85 \mathrm{mmHg})$, and this agrees with our study [25].

HE is a well-known complication of patients with liver cirrhosis after portosystemic shunt. In recent years, TIPS has been accepted as minimally invasive therapy for complications of portal hypertension recurrent bleeding from varices, refractory ascites, and liver failure due to Budd-Chiari syndrome. Because TIPS resembles a surgical side-to-side shunt, an increased rate of HE can be seen after TIPS; the higher incidence of HE after TIPS has attracted the interest of researches in investigating the causative factors for HE. Besides, predicting factors of HE after TIPS have been much controversial. 


\section{Conclusion}

Patients with hepatofugal flow in the portal vein are perfect candidates for TIPS than patients with hepatopetal flow in the portal vein.

\section{Recommendation}

Further research should be done to analyze the efficacy of TIPS in HRS cases. Further research should be done to standardize the use of Child score and pre-TTPS HE as good predictors of post-TIPS HE.

\section{Abbreviations}

HE: Hepatic encephalopathy; TIPS: Transjugular intrahepatic portosystemic shunt; HCV: Hepatitis C virus; HBV: Hepatitis B virus; SD: Standard deviation

\section{Acknowledgements}

No grant or other financial support was received for this study. Forms of support received by each author for this study included a good selection of cases, instructive supervision, continuous guidance, valuable suggestions, and good instructions.

Our paper is an extended version of the selected abstract by the Committee of the 29th Asian Pacific Association for the Study of the Liver (APASL) 2020 in Bali, Indonesia, to be presented as a part of the Scientific Program under the theme of "Golden Ages of Hepatology" (abstract submission no.: APASL2020-ABS477)

\section{Authors' contributions}

All authors have read and approved the manuscript. All authors have agreed both to be personally accountable for the author's own contributions and to ensure that questions related to the accuracy or integrity of any part of the work, even the ones in which the author was not personally involved, are appropriately investigated, resolved, and the resolution documented in the literature. HE was responsible for provision of study materials, patients, analysis, and acquisition of the financial support for the project leading to this publication and application of statistical, mathematical, computational, or other formal techniques to analyze or synthesize study data. MA performed the design of the work, managed activities to annotate (produce metadata), for initial use and later reuse plus ideas, and contributed to the formulation or evolution of overarching research goals and aims and acquisition of the financial support for the project leading to this publication. ET contributed to the management and coordination responsibility for the research activity planning and execution plus conception, verification, whether as a part of the activity or separate, of the overall replication/ reproducibility of results/experiments and other research outputs, and acquisition of the financial support for the project leading to this publication. $\mathrm{HZ}$ created and/or presented the published work, specifically in writing the initial draft (including substantive translation), and is responsible for the oversight and leadership responsibility for the research activity planning and execution, including mentorship external to the core team. He revised the work and contributed to the acquisition of the financial support for the project leading to this publication. SA was responsible for the programming, software development, designing computer programs, implementing the computer code and supporting algorithms, testing of existing code components, creating new software, and acquiring financial support for the project leading to this publication. ME conducted the research and investigation process, specifically performing the experiments or data/ evidence collection, conception, management, and coordination and is responsible for the research activity planning and execution and provision of study materials, instrumentation, or other analysis tools. El shared creation, presentation of the published work, specifically writing the initial draft (including substantive translation), interpretation of data and acquisition of the financial support for the project leading to this publication.

\section{Funding}

We did not receive any fund

\section{Ethics approval and consent to participate}

An informed written consent was obtained from all individual participants included in the study. The study was reviewed and approved by the ethical committee "N00189" at the National Liver Institute.

\section{Consent for publication}

All authors are in agreement with the content of the manuscript. On behalf of my colleagues, we have pleasure for dealing with your Journal. I would like to thank you, and I hope that our research work is under your kind care and observation.

\section{Competing interests}

The authors declare that there is no conflict of interest regarding the publication of this paper.

\section{Author details}

${ }^{1}$ Hepatology and Gastroenterology Department, National Liver Institute, Menoufia University, Yassin Abdel-Ghafar street, Shebeen El-Kom, Menoufia 32511, Egypt. ${ }^{2}$ Radiology Department, National Liver Institute, Menoufia University, Shebeen El-Kom, Egypt. ${ }^{3}$ National Liver Institute, Menoufia University, Shebeen El-Kom, Egypt.

Received: 9 December 2019 Accepted: 26 May 2020

Published online: 03 August 2020

\section{References}

1. Thomas D. Boyer, Conn HO, et al, Hepatology: a textbook of liver disease (4ail Philadelphia: Saunders (2003) 21:627-628.

2. Ibrahim ES, Alsebaey A, Zaghla H, Moawad Abdelmageed S, Gameel K, Abdelsameea $\mathrm{E}$ (2017) Long term rifaximin therapy as a primary prevention of hepatorenal syndrome. Eur J Gastroenterol Hepatol 29(11):1247-1250

3. Bonnel AR, Bunchorntavakul C, Rajender RK (2014) Transjugular intrahepatic portosystemic shunts in liver transplant recipients. Liver Transpl 20:130-139

4. Butteworth RF (2001) Neurotransmitter dysfunction in hepatic encephalopathy: new approaches and new findings. Metab Brain Dis 16:5565

5. Gerber TSH (2000) Hepatic encephalopathy in liver cirrhosis; pathogenesis. Diagnosis and management. Drugs 60:1353-1370

6. Berry K, Lerrigo R, Liou IW, loannou GN (2016) Association between transjugular intrahepatic portosystemic shunt and survival in patients with cirrhosis. Clin Gastroenterol Hepatol 14:118-123

7. Stefankova J, Fejfar T, Safka V, Hulek P, Krajina A, Fendrichova M (2002) Hepatic encephalopathy after TIPS retrospective study. Vnitriek 48:390-395

8. Tripathi D, Helmy A, Macbeth K, Balata S, Lui HF, Stanley AJ et al (2004) Ten years' follow-up of 472 patients following transjugular intrahepatic portosystemic stent-shunt insertion at a single centre. Eur J GastroenterolHepatol 16:9-18

9. Gaba RC, Parvinian A, Casadaban LC, Couture PM, Zivin SP, Lakhoo J et al (2015) Survival benefit of TIPS vs. serial paracentesis in patients with refractory ascites: a single institution case-control propensity score analysis. Clin Radiol 70:e51-e57

10. Khan S, Tudur SC, Williamson P, Sutton R (2006) Porto systemic shunts versus endoscopic therapy for varicealrebleeding in patients with cirrhosis. Cochrane Database Syst Rev:CD000553

11. Galal IF, Zakaria Z, Allam WR, Mahmoud MA, Ezzat AR, Osman A, Waked I, Strickland GT, Abdelwahab SF (2014) Cross reactive cellular immune response to HCV genotype 1 and 4 antigens among genotype 4 exposed subjects. PLoS One 9(6):e101264. https://doi.org/10.1371/journal.pone. 0101264 eCollection 2014

12. Abdelwahab SF, Zakaria Z, Sobhy M, Hamdy S, Mahmoud MA, Mikhail N, Allam WR, Rewisha E, Waked I (2015) Differential distribution of IL28B. rs12979860 single-nucleotide polymorphism among Egyptian healthcare workers with and without a hepatitis C virus-specific cellular immune response. Arch Virol 160(7):1741-1750. https://doi.org/10.1007/s00705-0152446-7 Epub 2015 May 15

13. Salerno F, Camma C, Enea M, Rossle M, Wong F (2007) Transjugular intrahepatic portosystemic shunt for refractory ascites: a meta-analysis of individual patient data. Gastroenterology 133:825-834

14. Saab S, Nieto JM, Lewis SK, Runyon BA (2006) TIPS versus paracentesis for cirrhotic patients with refractory ascites. Cochrane Database Syst Rev: CD004889 
15. Spiro H (1993) Clinical gastroenterology, 4thed. McGraw-Hill, New York, pp 1184-1188

16. Kramer L, Bauer E, Gendo A, Funk G, Madi C, Pidlich J et al (2002) Neurophysio logical evidence of cognitive impairment in patients without hepatic encephalopathy after transjagular intrahepatic portosystemic shunts. Am J Gastroenterol 97:162-166

17. Darryl A. Zuckerman, Michael D. Darcyi, Thomas P. Bocchini, Charles F. Hildebolt, AJR 1997; 169:1727-1731.

18. Dan Deng, Ming-Song Liao, Jian-Ping Qin and Xiao-An Li. Hepatobiliarypancreat Dis Int 2006; 5:232-236.

19. Sanyal AJ, Freedman AM, Shiffman ML, Purdum PP 3rd, Luketic VA, Cheatham AK (1994) Portosystemic encephalopathy after transjugular intrahepatic portosystemic shunt: results of a prospective controlled study. HEPATOLOGY 20:46-55

20. Sanyal AJ, Freedman AM, Luketic VA, Purdum P III, Shiffman M, Cole P, Tisnado J, Simmons S (1997) Transjugular intrahepatic portosystemic shunts compared with endoscopic sclerotherapy for the prevention of recurrent variceal hemorrhage. A randomized, controlled trial. Ann Intern Med 126: 849-857

21. Somberg KA, Riegler JL, LaBerge JM, Doherty-Simor MM, Bachetti P, Roberts J, Lake JR (1995) Hepatic encephalopathy after transjugular intrahepatic portosystemic shunts: incidence and risk factors. Am J Gastroenterol 90:549555

22. Schemmer P, Radeleff B, Flechtenmacher C, Mehrabi A, Richter GM, Buchler MW, Schmidt J (2006) TIPSS for variceal hemorrhage after living related liver transplantation: a dangerous indication. World I Gastroenterol 12:493-495

23. Ward TJ, Techasith T, Louie JD, Hwang GL, Hofmann LV, Sze DY (2015) Emergent salvage direct intrahepatic portocaval shunt procedure for acute variceal hemorrhage. J Vasc Interv Radiol 26:829-834

24. Oliviero R, Stefania A, Filippo S, Adriano D, Federica C, Alessin F, Adolfo F, Manuela M, AJG 2008:2738-2746.

25. Salem R, Vouche M, Baker T, Herrero Jl, Caicedo JC, Fryer J et al (2015) Pretransplant portal vein recanalization-transjugular intrahepatic portosystemic shunt in patients with complete obliterative portal vein thrombosis. Transplantation 99:2347-2355

\section{Publisher's Note}

Springer Nature remains neutral with regard to jurisdictional claims in published maps and institutional affiliations.

\section{Submit your manuscript to a SpringerOpen ${ }^{\circ}$ journal and benefit from:}

- Convenient online submission

- Rigorous peer review

- Open access: articles freely available online

- High visibility within the field

- Retaining the copyright to your article

Submit your next manuscript at $\boldsymbol{\nabla}$ springeropen.com 